\title{
METODE PENDIDIKAN KARAKTER ANAK USIA DINI (Studi Komparasi Pemikiran Zakiah Daradjat Dan Thomas Lickona)
}

\author{
Aulia Rahma', Marhumah' \\ Universitas Islam Negeri Sunan Kalijaga \\ Auliara627@gmail.com, Marhumah@uin-suka.ac.id
}

\begin{abstract}
ABSTRAC
Early childhood character education methods are ways to educate early childhood to have good character and apply it in daily life. The research is based on the background of the existence of a major challenge that must be faced by early childhood education (PAUD), namely, how to educate early childhood so that all the potential that exists in the standards of early childhood development can develop properly, which is moral / character development become one of them and become the first order that must be developed. As for one method must be done by educators, namely creating good relationships or interactions with children. because the quality of this interaction greatly affects the child's character development. But in reality there are not a few interactions that occur between educators and children that make children depressed. This is due to the use of the wrong method / method, such as (1) prohibiting children from crying; (2) discriminating children; (3) labeling children, for example "lazy children"; (3) prohibiting too often. Therefore, this research will be a theoretical study of the methods of early childhood character education. It is intended that educators both parents and teachers gain a deeper understanding of methods in early childhood character education.

The type of research used in this study is a research library, namely research which is a type of research that limits its activities to library collection materials without the need to conduct field research. In this case the researcher referred to the thinker Zakiah Daradjat and Thomas Lickona who were the leaders of character education. This thesis aims to find out both of their thoughts about early childhood character education methods which will then be analyzed by comparing the thoughts of both. The data sources in this study were obtained from primary data (principal) and secondary data (supporting or supporting primary data). Furthermore, the approach used in this study is a comparative approach.

From the results of the study it is known that the thinking of early childhood character education methods Zakiah Darajat includes (1) the formation of pre-birth character, namely, character formation through the selection of partners and formation of the character of the child in the womb, (2) character formation of children after birth, that is, through family, school and community environment. As for some of the methods put forward, such as forming characters through good example, mental development, conducting screening of foreign cultures, improving religious education, and so forth. While the method of forming early childhood character according to Thomas Lickona is divided into three parts, namely: (1)
\end{abstract}


methods of forming children's character in the family, such as teaching children by giving examples of good behavior, using direct teaching to shape conscience and habits, teaching decisions that good, etc.; (2) methods for forming children's character in schools, namely by giving children the opportunity to practice virtue, involving the entire school community in encouraging; good character, building a moral community in the classroom, and so on. (3) methods for the formation of children's character in society, such as integrating characters in all community programs in the community, creating leadership groups, the existence of government policies such as leave for parents which aims to form an inner bond between parents and children and so forth. Thought both have their own characteristics and have similarities and differences. However, with the difference in style of thought both can be collaborated to give birth to a new concept which is not only to prepare a generation that has good character, but also equipped with Islamic characters.

Keywords: Method, Character Education, Zakiah Daradjat, Thomas Lickona.

\begin{abstract}
ABSTRAK
Adapun penelitian ini dilatar belakangi oleh adanya sebuah tantangan besar yang harus dihadapi pendidikan anak usia dini (PAUD) yaitu, bagaimana cara mendidik anak usia dini agar segala potensi yang ada dalam standar perkembangan anak usia dini dapat berkembang sebagaimana mestinya, yang mana perkembangan moral/karakter menjadi satu diantaranya dan menjadi urutan pertama yang harus dikembangkan. Adapun salah satu cara/metode harus dilakukan oleh pendidik yaitu menciptakan hubungan atau interaksi yang baik dengan anak. karena kualitas interaksi ini sangat mempengaruhi perkembangan karakter anak. Namun pada kenyataannya tidak sedikit interaksi yang terjadi antara pendidik dengan anak justru membuat anak tertekan. Hal ini dikarenakan penggunaan cara/metode yang salah, seperti (1) melarang anak menangis; (2) membeda-bedakan anak; (3) labeling pada anak, contoh "anak pemalas"; (3) terlalu sering melarang. Maka dari itu, penelitan ini akan kajian secara teorotis tentang metode pendidikan karakter anak usia dini. Hal ini bertujuan agar para pendidik baik itu orang tua maupun guru memperoleh pemahaman yang lebih mendalam mengenai metode dalam pendidikan karakter anak usia dini.

Adapun jenis penelitian yang digunakan dalam penelitian ini adalah library research yaitu penelitian yang yaitu jenis penelitian yang membatasi kegiatannya pada bahan-bahan koleksi perpustakaan tanpa perlu melakukan riset lapangan. Dalam hal ini peneliti merujuk pasa pemikran Zakiah Daradjat dan Thomas Lickona yang merupakan tokoh penggagas pendidikan karakter. Tesis ini bertujuan untuk mengetahui pemikiran keduanya tentang metode pendidikan karakter anak usia dini yang kemudian akan dianalisis dengan membandingkan pemikiran keduanya. Adapun sumber data dalam penelitian ini diperoleh dari data primer (pokok) dan data
\end{abstract}


sekunder (penunjang atau pendukung data primer). Selanjutnya, pendekatan yang digunakan dalam penelitian ini adalah pendekatan komparatif.

Dari hasil penelitian diketahui bahwa, pemikiran metode pendidikan karakter anak usia dini Zakiah Darajat meliputi, (1) pembentukan karakter anak sebelum lahir yaitu, pembentukan karakter melalui pemilihan pasangan dan pembenutukan karakter anak dalam kandungan, (2) pembentukan karakter anak setelah lahir yaitu, melalui lingkungan keluarga, sekolah, dan masyarakat. Adapun beberapa metode yang dikemukakan seperti membentuk karakter melalui contoh/teladan yang baik, pembinaan mental, mengadakan penyaringan terhadap kebudayaan asing, meningkatkan pendidikan agama, dan lain sebagainya. Sedangkan metode pembentukan karakter anak usia dini menurut Thomas Lickona terbagi dala tiga bagian yaitu: (1) metode pembentukan karakter anak dalam keluarga, seperti mengajarkan kepada anak dengan memberi contoh perilaku yang baik, menggunakan pengajaran langsung untuk membentuk hati nurani dan kebiasaan, mengajarkan keputusan yang baik, dan lain sebagainya; (2) metode pembentukan karakter anak dalam sekolah, yaitu dengan memberikan kesempatan kepada anak untuk mempraktikkan kebajikan, melibatkan seluruh komunitas sekolah dalam mendorong; karakter yang baik, membangun komunitas moral dalam kelas, dan lain sebagainya. (3) metode pembentukan karakter anak dalam masyarakat, seperti mengintegrasikan karakter dalam seluruh program komunitas yang ada di masyarakat, menciptakan kelompok kepemimpinan, adanya kebijakan dari pemerintah seperti, adanya cuti untuk para orang tua yang bertujuan agar terbentuknya ikatan batin atara orang tua dan anak, dan lain sebagainya. Pemikiran keduanya memiliki karakteristik masingmasing serta memiliki persamaan dan perbedaan. Namun, dengan adanya perbedaan corak pemikian dari keduanya bisa dikolaborasikan untuk melahirkan sebuah konsep baru yaitu tidak hanya menyiapkan generasi yang memiliki karakter baik, namun juga dilengkapi dengan karakter-karakter Islami.

Kata Kunci: Metode, Pendidikan Karakter, Zakiah Daradjat, Thomas Lickona.

\section{A. PENDAHULUAN}

Tantangan besar yang harus dihadapi PAUD salah satunya adalah bagaimana cara mendidik anak usia dini agar segala potensi yang ada dalam standar perkembangan anak usia dini dapat berkembang sebagaimana mestinya. ${ }^{1}$ Adapun perkembangan moral menjadi satu diantaranya dan menjadi urutan pertama yang harus dikembangkan, olehkarenanya pendidikan karakter menjadi sebuah ide dan

${ }^{1}$ Mursid, Pengembangan Pembelajaran PAUD, (Bandung: Remaja Rosda Karya, 2015), hlm. 2. 
tawaran yang revolusioner bagi perkembangan moral/karakter anak. ${ }^{2}$ Pendidikan karakter menjadi sangat penting bagi anak usia dini agar anak matang dalam mengolah emosi, dan inilah yang merupakan bekal penting dalam mempersiapkan anak usia dini menyongsong masa depan yang penuh tantangan. ${ }^{3}$

Adapun salah satu cara/metode harus dilakukan oleh pendidik yaitu menciptakan hubungan atau interaksi yang baik dengan anak. karena kualitas interaksi ini sangat mempengaruhi perkembangan karakter anak. Namun pada kenyataannya tidak sedikit interaksi yang terjadi antara pendidik dengan anak justru membuat anak tertekan. Hal ini dikarenakan penggunaan cara/metode yang salah, seperti yang dikatakan seorang psikolog yaitu Rustika Thamrin, yang dikutip oleh Syamsul Kurniawan, bahwa beberapa cara atau prilaku yang sering dilakukan oleh orang tua maupun guru yang dapat membuat anak tertekan, stres, dan depresi yaitu sebagai berikut: (1) melarang anak menangis; (2) membeda-bedakan anak; (3) labeling pada anak, contoh "anak pemalas"; (3) terlalu sering melarang. ${ }^{4}$ Hal tersebut tidak bisa kita sangkal karena tentu kita juga sering menjumpai orang tua/ guru yang mengunakan cara-cara tersebut, atau bahkan kita termasuk salah satu yang pernah mengalaminya.

Berdasarkan pemaparan di atas maka, peneliti menganggap perlunya kajian secara teorotis tentang metode pendidikan karakter anak usia dini. Hal ini bertujuan agar para pendidik baik itu orang tua maupun guru memperoleh pemahaman yang lebih mendalam mengenai metode dalam pendidikan karakter anak usia dini. Untuk itu, penulis melakukan penelitian dan mengkaji terhadap pemikiran dua tokoh yang berpengaruh dalam pendidikan karakter di Indonesia dan Barat yaitu, Zakiah hlm. 7 .

${ }^{2}$ Agus Wibowo, Pendidikan Karakter Berbasis Sastra, (Yogyakarta: Pustaka Pelajar, 2013),

${ }^{3}$ Sudaryanti, Pentingnya Pendidikan Karakter Bagi Anak Usia Dini Dalam Jurnal Pendidikan Anak, Universitas Negeri Yogyakart, Volume 1 Edisi 1 Juni 2012, hlm. 5.

${ }^{4}$ Syamsul Kurniawan, Pendidikan Karakter: Konsepsi Dan Implementasinya Secara Terpadu Di Lingkungan Keluarga, Sekolah, Perguruan Tinggi, \& Masyarakat (Yogyakarta: Ar-Ruzz Media, 2013), hlm. 65. 
Daradjat Thomas Lickona. Adapun peneliti memilih dua tokoh ini disebabkan oleh beberapa alasan diantaranya:

Pertama, keduanya mempunyai kedudukan yang setara jika dilihat dari ketokohannya, hal ini menjadi begitu penting mengingat penelitian ini merupakan penelitian komparatif. Dalam hal ini Zakiah Daradjat dan Thomas Lickona samasama orang yang berkontribusi dalam dunia pendidikan dan pskologi, yaitu sebagai pendidik dan ahli psikologi, serta sama-sama memiliki perhatian yang besar terhadap persoalan karakter anak. Hal ini terlihat dari pemikiran keduanya yang akan dibahas lebih lanjut dalam bab berikutnya. Kedua, karena kedua tokoh sangat konsisten dalam mengemukakaan gagasan atau ide mengenai metode dalam pendidikan karakter, dibandingan dengan tokoh-tokoh lainnya yang membahas mengenai pendidikan karakter secara umum. Ketiga, peneliti ingin membandingkan pemikiran tokoh Indonesia dan tokoh yang Barat. Dimana keduanya berbeda dalam hal kebudayaan maupun kepercayaan. Yang mana perbedaan tersebut akan mempengaruhi gagasan-gagasan dari keduanya. Keempat, kedua tokoh ini merupakan dua orang yang sangat berpengaruh dan banyak memberikan kontribusi, serta memiliki karya-karya yang monumental dalam bidang pendidikan karakter.

Banyak hal menarik dari kedua tokoh di atas, baik dari karyanya, sudut pandangnya dalam melihat suatu permasalahan, serta kontribusi keduanya dalam pendidikan karakter khususnya pendidikan karakter anak usia dini. Untuk itu peneliti mengkajinya dalam sebuah judul: Metode Pendidikan Karakter Anak Usia Dini (Studi Komparasi Pemikiran Zakiah Daradjat dan Thomas Lickona).

\section{B. METODE PENGUMPULAN DATA}

Penelitian ini termasuk penelitian kepustakaan (library reseach), yaitu jenis penelitian yang membatasi kegiatannya hanya pada bahan-bahan koleksi 
perpustakaan saja tanpa perlu melakukan riset lapangan. ${ }^{5}$ Dengan menggunakan pendekatan deskriptif analisis, yaitu pencarian berupa fakta, hasil dan ide pemikiran seseorang melalui cara mencari, menganalisis, membuat interpretasi serta melakukan generalisasi terhadap hasil penelitian yang dilakukan. ${ }^{6}$

\section{HASIL DAN PEMBAHASAN}

\section{Karakteristik Metode Pendidikan Karakter Anak Usia Dini Menurut Zakiah Daradjatdan Thomas Lickona}

\section{a. Zakiah Daradjat}

Karakteristik lain dari metode pendidikan karakter anak usia dini menurut Zakiah Daradjat yaitu dalam lingkup sekolah, Zakiah Daradjat mengungkapkan bahwa pembinaan karakter anak usia dini di sekolah bisa melalui contoh/teladan dari gurunya, dikarenakan pada usiia 0-6 tahun anak belum mampu berpikir secara abstrak atau maknawi. Pada usia ini menurut Zakiah anak hanya mampu berpikir secara indrawi anak belajar melalui apa yang ia lihat, apa yang dia dengar, apa yang iarasa dan lain sebagainya. Sehingga menurut Zakiah Daradjat metode teladan atau pemberian contoh merupakan metode yang sangat efektif yang bisa diserap oleh anak usia dini. Untuk itu dalam metode pendidikan karakter anak usia dini di lingkunagan sekolah Zakiah Daradjat lebih terfokus pada kepribadian yang harus dimiliki oleh seorang guru sebelum mengajarkan karakter pada anak didiknya. Dalam hal ini, Zakiah tidak mengemukakan apa-apa saja metode yang paraktis yang bisa diterapkan oleh guru maupun pihak sekolah.

Selanjutnya metode pendidikan karakter Zakiah Daradjat dalam lingkungan masyarakat, berdasarkn pemaparan pada bab sebelumnya bisa kita pahami bahwa metode pendidikan karakter Zakiah Daradjat banyak melibatkan masyarakat secara

\footnotetext{
${ }^{5}$ Mwstika Zed, Metode Penelitian Kepustakaan, (Jakarta: Yayasaan Obor Indinesia, 2004),
} hlm. 2 .

${ }^{6}$ Munzir, Metodologi Penelitian Pendidikan, (Jakarat: Rajawali Press, 2005), hlm. 62. 
luas, dimana ia tidak hanya mengemukakn metode yang bias dilakukan oleh para tokoh masyarakat dan pemerintah melainkan juga melibatkan media masa.

\section{b. Thomas Lickona}

Thomas Lickona mengemukakan suatu metode yang bisa diterapkan oleh sekolah untuk menjalin kerja sama dengan keluarga atau orang tua siswa. Menurutnya lingkungan keluarga dan sekolah harus saling bekerja sama dalam mensukseskan pendidikan karakter. Selain itu keterlibatan orang tua mrupakan indikator utama bagi kesuksesan sekolah dalam mewujudkan pendidikan karakter. Adapun untuk membantu para orang tua memenuhi peran utamanya sebagai guru moral ia mengemukakan beberapa metode seperti menyediakan program tentang parenting, membentuk forum untuk orang tua, dan lain sebagainya.

Selain beberapa karakteristik di atas pemikiran Thomas Lickona mengenai metode pendidikan karakter anak usia dini juga lebih cederung berlandaskan pada niai-nilai kebudayaan dan tidak berlandaskan atau tidak memasukan unsur agama didalamnya. Selanjutnya metode pendidikan karakter Thomas Lickona juga banyak berfokus pada pelaksanaan pendidikan karakter anak usia dini di keluarga dan sekolah.

\section{Persamaan dan Perbedaan Metode Pendidikan Karakter Anak Usia Dini Menurut Zakiah Daradjat dan Thomas Lickona \\ 1) Persamaan}

Berdasarkan penjelasan yang telah dipaparkan pada bab sebelumnya, dapat diphami bahwa persamaan metode pendidikan karakter anak usia dini menurut Zakiah Daradjat dan Thomas Lickona yaitu, semua metode yang dikemukakan samasama bertujuan untuk menyiapkan generasi yang akan datang agar menjadi generasi yang berkarakter, dan usaha-usaha dalam penggunaan metode pendidikan karakter keduanya sama-sama melibatkan semua pihak untuk ikut andil dalam pembentukan karakter anak, dimana keduanya sama-sama mengemukakan metode pendidikan karakter anak usia dini yang bisa diterapkan dalam lingkungan keluarga, sekolah, dan 
masyarakat. Dari beberapa metode yang dikemukakan terlihat bahwa keduanya samasama mengemukakan metode yang efektif dalam pendidikan karakter anak usia dini yaitu metode pemberian contohatau teladan.

\section{2) Perbedaan}

Perbedaan metode pendidikan anak usia dini pemikiran Zakiah Daradjat dan Thomas Lickona yaitu, keduanya berbeda dalam hal sumber/landasan yang dijadikan sebagai metode pendidikan karakternya, dimana Zakiah Daradjat banyak mengemukakan metode pendidikan karakter anak yang bersumber dari ajaran agama (Islam), bahkan dalam upaya membina karakter anak ia menyarankan agar para pendidik mengikuti cara-cara yang sesuai dengan ajaran Islam yaitu tidak hanya dalam hal beribadah, tetapi juga dalam hal berucap dan berperilaku. Sedangkan jika kita telaah pemikiran Thomas Lickona mengenai metode pendidikan karakter anak usia dini, terlihat bahwa pemikirannya berlandaskan pada nilai-nilai moral yang berlaku dalam sebuah masyarakat atau niai-nilai kebudayaan. Sehingga dalam penjelasannya mengenai metode pendidikan anak usia dini ia tidak menyinggung suatu cara atau metode yang berdasarkan pada suatu ajaran agama tertentu.

Perbedaan selanjutnya dari pemikiran Zakiah Daradjat dan Thomas Lickona juga terletak pada pembahasan ruang lingkup metode pendidikan karakter anak usia dini, dimana Zakiah Daradjat lebih menyeluruh dengan menambahkan metode pendidikan karakter anak usia dini sebelum lahir yaitu,, metode pendidikan karakter anak melalui pemilihan pasangan dan metode pendidikan karakter anak saat dalam kandungan, dimana dalam hal ini Thomas Lickona tidak membahasnya. Menurut analisis peneliti mengapa ada perbedaan dalam pemikiran keduanya, hal ini berkaitan dengan dasar yang dijadikan sebagai metode pendidikan karakter keduanya, seperti yang telah disebutkan sebelumnya bahwa Zakiah Daradjat menjadikan ajaran agama Islam sebagai landasannya, yang mana dalam hal ini Islam telah mengajarkan bagaimana cara memilih pasangan yang baik dengan kriteria tertentu, dan ternyata hal ini dibuktikan oleh Zakiah bahwa dalam memilih pasangan ternyata akan 
berpengaruh terhadap pendidikan karakter anak lebih lanjut Islam juga mengajarkan penddikan pranatal yang mana hal ini juga akan berpengaruh terhadap karakter anak kelak.

Selain bebrapa perbedaan di atas, peneliti juga menemukan perbedaan dalam hal metode pendidikan karakter anak usia dini di sekolah dimana dalam hal ini, Zakiah Daradjat hanya mengemukakan tiga metode yaitu: (1) pendidikan karakter melalui contoh/teladan; (2) pembiasaan; (3) permainan di dalam maupun diluar kelas, dan segala tempat yang tampak oleh anak semuanya harus baik dan juga bernafaskan Islam. Sedangkan Thomas Lickona mengemukakan berbagai macam metode disertai langkah-langkanya yang bisa diterapkan tidak hanya oleh guru tetapi juga oleh semua pihak di lingkungan sekolah. Selain itu ia juga mngemukakan metode yang bisa diterapkan oleh pihak sekolah untuk menjalin kerja sama dengan orang tua sebagai mitra dalam pendidikan karakter. Selanjutnya Thomas Lickona mengemuakan metode yang bisa diterapkan oleh pihak sekolah untuk mewujudkkan pendidikan krakter dengan melibatkan seluruh komunitas yang ada di dalam lingkungan sekolah, serta metode yang bisa dilakukan oleh guru dalam mengajarkan krakter baik dalam proses pembelajaran di dalam maupun di luar kelas. Sehingga dari sini dapat kita pahami bahwa metode pendidikan karakter dalam lingkungan sekolah, pemikiran Thomas Lickona dianggap lebih lengkap serta menyeluruh karna meliputi berbagai macam metode yang tidak hanya bisa diterapkan oleh guru melainkan berbagai metode yang bisa diterapkan juga oleh pihak sekolah, dan jika kita perhatikan lebih dalam metode pendidikan karakter Thomas Lickona memang lebih banyak berfokus pada pendidikan karakter di lingkungan sekolah, ia juga menyebutkan bahwa sekolah merupakan tempat yang paling berperan dalam mewujudkan pendidikn karakter.

Selanjutnya yaitu perbedaan metode pendidikan karakter dalam lingkungan masyarakat, berdasarkn pemaparan pada bab sebelumnya bisa kita pahami bahwa metode pendidikan karakter Zakiah Daradjat lebih banyak melibatkan masyarakat secara luas, dimana ia tidak hanya mengemukakn metode yang bias dilakukan oleh para tokoh masyarakat dan pemerintah melainkan juga melibatkan media masa. Hal 
ini berbeda dengan metode yang dikemukakan oleh Thomas Lickona, dalam hal ini ia mengemukakan metode yang melibatkan segelintir komunitas dalam masyarakat dan juga pemerintah. Adapun perbedan dari kedunya menurut peneliti hal ini dikarenakan keduanya hidup dalam kondisi dan situasi masyarakat yang berbeda dengan berbaggai perasalan yang berbeda pula, sehingga pemikiran dari keduanyapun lahir dari konndisi masyarakat tersebut yang merupakan solusi dari permasalah pendidikan karakter yang ada dalam masyarakat keduanya.

\section{KESIMPULAN}

1. Metode pendidikan karakter anak usia dini pemikiran Zakiah Daradjat meliputi, metode pendidikan karakter anak sebelum lahir, yaitu melalui pemilihan pasangan dan metode pembentukan karakter saat anak dalam kandungan. Selain itu ia juga, mengemukakan metode pendidikan karakter setelah anak lahir yang yang berlangsung dalam keluarga, sekolah dan masyarakat.

2. Metode pendidikan karakter anak usia dini pemikiran Thomas Lickona lebih cenderung kepada metode yang praktis beserta langah-langkahnya yang bisa langsung diterapkan oleh para pendidik dalam pendidikan karakter. Dimana ia mengemukakan begitu banyak metode yang bisa diterapkan dalam pendidikan karakter terutama pendidikan karakter di sekolah.

3. Perbandingan metode pendidikan karakter Zakiah Daradjat dan Thomas Lickona diwarnai dengan perbedaan corak pandangan masing-masing yang tentunya tidak melahirkan suatu jurang pemisah, melainkan dapat dikolaborasikaan untuk melahirkan suatu pemahaman baru tentang metode pendidikan karakter anak usia dini. 


\section{E. DAFTAR PUSTAKA}

Ahsani, Muhammad, Studi Komparasi Pemikiran Thomas Lickona dan Abdullah Nashih Ulwan Tentang Pendidikan Karakter Keluarga dan Sekolah, dalam jurnal Didaktika Religia, Volume 2, No. 2 Tahun 2014.

Aisyah, Siti dkk, Perkembangan dan Konsep Dasar Pengembangan Anak Usia Dini (Jakarta: UniversitasTerbuka, 2011.

Baker, Anton, Metode-Metode Penelitian Filsafat, Yogyakarta: Kanisius, 1994.

Budiyono, Alief, Meningkatkan Moralitas Remaja Melalui Dukungan Sosial, dalam jurnal Komunika, Vol. IV, No. 2, Juli, 2010.

Burhanudin, Jajat Ulama Perempuan Indonesia, (Jakata: PT Gramedia Pustaka Utama, 2002Sudarto, Metodologi Penelitian Filsafat, Jakarta: PT Raja Grafindo, 2001.

Daradjat, Zaikah, Membina Nilai-Nilai Moral Di Indonesia, Jakarta: Bulan Bintang, 1977. , Kebahagiaan, Jakarta:Ruhama,1988.

, Kepribadian Guru, Jakarta: Bulan Bintang Zakiah Daradjat, Cet. Ke-4, Jakarta: Bulan Bintang, 2005.

, Ilmu Jiwa Agama, Jakarta: Bulan Bintang, 2003.

, Ilmu Pendidikan Islam, (Jakarta: Bumi Aksara, 2009.

, Islam Dan Peranan Wanita, Jakarta: Bulan Bintang, 1978.

, Pembinaan remaja, Jakarta: Bulan Bintang, 1976.

, Pendidikan Islam dalam Keluarga Dan Sekolah, Jakarta: Ruhama, 1995.

,Peranan Agama Dalam Kesehatan Mental, Jakarta: Hajimas Agung tt.

, Perbandingan Agama I (Jakarta: Bumi Aksara, 1996.

, Psikoterapi Islami, (Jakarta: Bulan Bintang, 2002.

, Remaja Harapan dan Tantangan, Jakarta: Ruhama, 1995.

Elfan Fanhas, Gina Nurazizah Mukhlis, Pendidikan Karakter Untuk Anak Usia Dini Menurut Q.S. Lukman : 13 - 19, dalam jurnal Pedagogi: Jurnal Anak Usia Dini dan Pendidikan Anak Usia Dini, Volume 3 Nomor 3a Desember 2017.

Ghazali, Al, Ihya' al- 'ulum al-Diin, terj. Moh. Zuhri, dkk, semarang: As-Syifa, 2009.

Gunadi, R. Andi Ahmad, Membentuk Karakter Melalui Pendidikan Moral Pada Anak Usia Dini Di Sekolah Raudhatul Athfal (R.A) Habibillah dalam Jurnal Ilmiah Widya, Volume 1 Nomor 2 Juli-Agustus 2013.

Hasnawati, Ratna, Membangun Karakter Pada Usia Emas, dalam Jurnal Ilmiah Mahasiswa Pendidikan Anak Usia Dini, Vol. 1, No. 1, Agustus 2016.

Heldanita, Pendidikan Karakter Anak Usia Dini (Stdi Komparasi Pemikiran Thomas Lickona Dan Al-Ghazali), yogyakarta: Proram Magister UIN Sunan Kalijaga 2017.

Helmawati, Pendidikan Keluarga: Teoritis Dan Praktis, Bandung: PT. Remaja Rosdakarya, 2014. 
Hidayati, Abna dkk, The Development Of Character Education Curriculum For Elementary Student In West Sumatera, dalam Jurnal Pendidikan dan Penelitian Internasional, Vol. 2 No. 6 Juni 2014.

Hidayatullah, M. Furqon, Guru Sejati: Membangun Insan Berkarakter Kuat dan Cerdas,Surakarta: Yuma Pustaka, 2009.

Johansyah, Penidikan Karakter dalam Islam, dalam jurnal Ilmiah Islam Futura, Vol. IX, No 1, Agustus 2011.

Judiani, Sri, Implementasi Pendidikan Karakter di Sekolah Dasar Melalui Penguatan Pelaksanaan Kurikulum, dalam jurnal Pendidikan dan Kebudayaan, Vol. 16, Edisi Khusus III, Oktober 2010.

Kartono, Kartini, Pengantar Metodologi Research, Bandung: Tarsiti, 2000.

Kaelan, Metode Penelitian Kualitatif Interdisipliner, Yogyakarta: Paradigma, 2012.

Khaliq, Abd, Pendidikan Karakter Dalam Perspektif Kitab Ayyuhal Walad; Konstruksi Pemikiran Imam Al-Ghazali, dalam Jurnal Al-Ibroh, vol 2, no. 1, Mei 2017.

Khan, Yahya, Pendidikan Karakter Berbasis Potensi Diri, Yogyakarta: Pelangi Publishing, 2010.

Koesoema, Doni, Pendidikan Karakter: Strategi Mendidik Anak di Zaman Global, Jakarta: Grafindo, 2010.

Kurniawan, Syamsul, Pendidikan Karakter: Konsepsi Dan Implementasinya Secara Terpadu Di Lingkungan Keluarga, Sekolah, Perguruan Tinggi, \& Masyarakat, Yogyakarta: Ar-Ruzz Media, 2013.

Kesuma, Dharma, Pendidikan Karakter Kajian Teori dan Praktek di Sekolah, Bandung: Remaja Rosdakarya, 2011.

Lickona, Thomas, Educating for Character: How Our School Can Teach Respect and Responsibility, New York: Bantam books, 1991.

, Mendidik Untuk Membentuk Krakter Bagaimana Sekolah Dapat Membeikan Pedidikan Tentang Sikap Hormat Dan Bertanggug Jawab, terj. Unyu, Jakarta: Bumi Aksara, 2013.

_. Character Matters: Persoalan Karakter Bagaimana Membantu Anak Mengembangkan Penilaian Yang Baik, integritas, dan kebajikan penting lainnya, terj. Juma Abdu Wamaungo dan jean antunes ruolf zien, jakarta: Bumi Aksara, 2016.

, "Entry In Moral Education: A Handbook" dalam mail.google.com, diakses pada 27/02/2019.

"VITA Thomas Lickona 2014" dalam mail.google.com, diakses pada 27/02/2019.

Majid, Abdul, Kepribadiandalam Psikologi Ilsam, Jakarta: PT Raja grafindo Persada, 2007.

Makin, Al, Mengenal Para Pemimpin Pascasarjana, Yogyakrta: Pascasarjana UIN Sunan Kalijaga Yogykarata, 2014. 
Magarustam, Filsafat Pendidikan Islam Menuju Pembentukan Karakter Menghadapi Arus Global, Yogyakarta: Pustaka Pelajar.

Marhumah, Kontekstualiasi Hadis dalam Pendidikan Karakter, Yogyakarta: SUKA Press, 2013.

Margono, Metodelogi Penelitian Penddikan, Jakarta: Rineka Cipta, 2010.

Marini, Arita Character Building Through Teaching Learning Process: Lesson In Indonesia, International Journal of Sciences and Research, Vol. 73, No. 5, May 2017.

Megawangi, Ratna Pendidikan Karakter Solusi Yang Tepat Untuk Membangun Bangsa, Jakarta: Indonesia heritage Foundation, 2007.

Mulyana, Rohmat, Mengartikulasikan Pendidikan Nlai, Bandung: Alfabeta, 2011.

Munir, Abdul Mulkhan, Kearifan Tradisional: Agama Bagi Manusia Atau Tuhan, Yogyakarta: UII Press, 2000.

Mursid, Pengembangan Pembelajaran PAUD, (Bandung: Remaja Rosda Karya, 2015.

Muslich, Masnur, Pendidikan Karakter Menjawab Tantangan Krisis Multidiensional, Jakarta : Bumi Aksara, 2013.

Nata, Abuddin, Manajemen Pendidikan: Mengatasi Kelemahan Pendidikan Islam di Indonesia, Jakarta: Kencana, 2003. , Ilmu pendidikan Islam, Jakarta: Kencana, 2016.

,Tokoh-Tokoh Pembaharuan Pendidikan Isam di Indonesia, Jakarta: PT Raa Grafino Persada, 2005.

Nasirudin, Pendidikan Tasawuf, Semarang: Rasail Media Group, 2009.

Nuraeni, Pendidikan Karakter Pada Anak Usia Dini” dalam jurnal Paedagogy, Vol. 1 No. 2, Oktober 2014.

Rubiyanto, Penidikan Karakter Menurut Perspektif Syed Muhammad Naquib AlAttas Dan Thomas Licona, Yogyakarta: FITK UIN Sunan Kalijaga, 2006.

Parjuangan, Pemikiran Zakiyah Daradjat Tentang Pembentukan Karakter dan Pengembangan Kreativitas Anak, Yogyakarta: Pascasarjana, UIN Sunan Kalijaga, 2017

Permendiknas No. 58 Tahun 2009.

Poerwadarminta, W.J.S. Kamus Umum Bahasa Indonesia, Jakarta: Balai Pustaka, 2006.

Risnawati, Vivit, Optimalisasi Pendidikan Karakter Anak Usia Dini Melalui Sentra Main Peran Di Taman Kanak-Kanak Padang, dalam jurnal Pesona PAUD Vol.1.No.1, 2012.

Salim, Haitami Pendidikan Anak Usia Dini Dalam Islam, Yogyakarta: Pustaka Pelajar, 2005.

Samani, Muchlas dan hariyanto, Konsep dan Model Pendidikan Karakter, (Bandung: Pt Remaja Rosda Karya, 2012. 
Sanjaya, Wina, Strategi Pembelajaran Berorientasi Standar Proses Pendidikan, Jakarta: Kencana Prenada Media Group, 2008.

Sapendi, Internalisasi Nilai-Nilai Moral Agama Pada Anak Usia Dini, dalam Jurnal At-Turats, Vol.9 Nomor 2, Desember Tahun 2015.

Sudaryanti, Pentingnya Pendidikan Karakter Bagi Anak Usia Dini dalam Jurnal

Pendidikan Anak, Universitas Negeri Yogyakart, volume 1 edisi 1 juni 2012.

Supriyadi, Dedi Mengangkat Citra dan Martabat Guru, Yogyakarta: Adicita Karya Nusa,1999.

Suyadi, Manajemen PAUD, Yogyakarta:Pustaka Pelajar, 2011.

Slamet Suyanto, Pendidikan Karakter untuk Anak Usia Dini, dalam Jurnal Pendidikan Anak, Volume 1, Edisi 1, Juni 2012.

Ulwan, Pendidikan Anak dalam Islam, Terjemahan Jamaludin Miri, Cet. III, Jakarta: Pustaka Amani, 2007.

Undang-Undang SISDIKNAS (Sistem Pendidikan Nasional) Tahun 2003.

Wibowo, Agus, Pendidikan Karakter Anak Usia Dini, Yogyakarta: Pustaka Pelajar, 2017.

Yati, Patmi Pendidikan Karakter Aak Usia Dini Melalui Metode Pembelajaran Field Trip, dalam jurnal Lentera, Vol. XVIII, No. 1, 2016.

Yanuardianto, Elga, Pendidikan Karakter Anak (Studi Komparasi Pemikiran Thomas Lickon dan Abdullah Nashih Ulwan), yogyakarta: Pascasarjana UIN Sunan Kalijaga, 2015.

Zainudin, Seluk Beluk Pendidikan Al-Ghazali, Jakarta: Bumi Aksara, 1991.

Zuchdi, Darmiyati, Humanisasi Pendidikan: Menemukan Kembali Pendidikan yang Manusiawi, Jakarta: Bumi Aksara, 2009.

Zed, Mwstika, Metode Penelitian Kepustakaan, Jakarta: Yayasaan Obor Indinesia, 2004.

Arief Burhan, biografi prof. Dr. Zakiah Daradjat, http: //a2dcollection. blogspot. com/2015 /10/ biografi-prof-dr-zakiah-daradjat, diakses pada 07 Januari 2019.

Ibnu Hasan, Biografi Prof. Dr. Zakiah Daradjat, http://dwcorp.blogspot.co.id/2015/04/prof-dr-zakiah-daradjat.html diakses pada 28/12/2018. 22.52 WIB.

NN, State univesity of New York's Staff "Thomas Lickona", http//www.cortland.edu.centers/character.staf.dot, diakses pada 02 january 2019. 